\title{
Periodic Mechanical Stress INDUCES Chondrocyte Proliferation and Matrix Synthesis via CaMKII-Mediated Pyk2 Signaling
}

\author{
Wenwei Liang ${ }^{a}$ Zeng Lia Zhen Wanga Jinchun Zhou ${ }^{a}$ Huanghe Song ${ }^{a}$ Shun Xu ${ }^{b}$ \\ Weiding Cui ${ }^{a}$ Qing Wang ${ }^{\text {a }}$ Zhefeng Chen ${ }^{\text {a }}$ Feng Liu ${ }^{a}$ Weimin Fan ${ }^{\mathrm{a}}$ \\ ${ }^{a}$ Department of Orthopedics, The First Affiliated Hospital of Nanjing Medical University, Nanjing, \\ bDepartment of Orthopedics, Huashan Hospital, Fudan University, Shanghai, China
}

\section{Key Words}

Periodic mechanical stress - Chondrocyte proliferation - Matrix synthesis - CaMKII • Pyk2 • Integrin $\beta 1$

\begin{abstract}
Background/Aims: Periodic mechanical stress can promote chondrocyte proliferation and matrix synthesis to improve the quality of tissue-engineered cartilage. Although the integrin $\beta 1-E R K 1 / 2$ signal cascade has been implicated in periodic mechanical stress-induced mitogenic effects in chondrocytes, the precise mechanisms have not been fully established. The current study was designed to probe the roles of CaMKII and Pyk2 signaling in periodic mechanical stress-mediated chondrocyte proliferation and matrix synthesis. Methods: Chondrocytes were subjected to periodic mechanical stress, proliferation was assessed by direct cell counting and CCK-8 assay; gene expressions were analyzed using quantitative real-time PCR, protein abundance by Western blotting. Results: Mechanical stress, markedly enhanced the phosphorylation levels of Pyk2 at Tyr ${ }^{402}$ and CaMKII at Thr ${ }^{286}$. Both suppression of Pyk2 with Pyk2 inhibitor PF431396 or Pyk2 shRNA and suppression of CaMKII with CaMKII inhibitor KN-93 or CaMKII shRNA blocked periodic mechanical stress-induced chondrocyte proliferation and matrix synthesis. Additionally, either pretreatment with $\mathrm{KN}-93$ or shRNA targeted to CaMKII prevented the activation of ERK1/2 and Pyk2 under conditions of periodic mechanical stress. Interestingly, in relation to periodic mechanical stress, in the context of Pyk2 inhibition with PF431396 or its targeted shRNA, only the phosphorylation levels of ERK1/2 were abrogated, while CaMKII signal activation was not affected. Moreover, the phosphorylation levels of CaMKII- Thr ${ }^{286}$ and Pyk2- $\mathrm{Tyr}^{402}$ were abolished after pretreatment with blocking antibody against integrin $\beta 1$ exposed to periodic mechanical stress. Conclusion: Our results collectively indicate that periodic mechanical stress promotes chondrocyte proliferation and matrix synthesis through the integrinß1-CaMKII-Pyk2-ERK1/2 signaling cascade.




\section{Cellular Physiology Cell Physiol Biochem 2017;42:383-396 \\ \begin{tabular}{ll|l} 
and Biochemistry Published onlıne: May 26, 2017 & $\begin{array}{l}\text { C } 2017 \text { The Author(s). Published by S. Karger AG, Basel } \\
\text { www.karger.com/cpb }\end{array}$ \\
\hline
\end{tabular} \\ Liang et al.: CaMKII-Mediated Pyk2 Signaling}

\section{Introduction}

Periodic mechanical stress has been confirmed to be a key regulator in enhancing the quality of tissue-engineered cartilage by promoting chondrocyte proliferation and matrix synthesis [1-4]. Aggrecan and collagen II are the two main cartilaginous matrix molecules that playing important roles in the process of chondrogenesis. However, the detailed mechanisms underlying the response of chondrocytes to periodic mechanical stress remains obscure. Integrin-initiated MAPK activation has been demonstrated to play crucial roles in mechanotransduction in many non-chondrocytic cell types [5-7]. We also identified that integrin $\beta 1$-ERK1/2 signals mediated periodic mechanical stress-induced chondrocyte proliferation and matrix synthesis, but other important signaling molecules involved in the signal cascade remain to be determined $[1,2,4]$.

Calmodulin-dependent kinase II (CaMKII), a multifunctional serine/threonine kinase, was confirmed to be a critical regulator of $\mathrm{Ca}^{2+}$ signaling in various signal pathways. It is widely accepted that when intracellular $\mathrm{Ca}^{2+}$ increases, $\mathrm{Ca}^{2+}$ and calmodulin (CaM) combine together to form the $\mathrm{Ca}^{2+} / \mathrm{CaM}$ complex, which then binds and activates CaMKII to mediate multiple cellular biological effects, including proliferation, migration and apoptosis [8-12]. In our previous study, we demonstrated that PLC $\gamma 1$, known as an important serine threonine kinase of PLC, is activated in response to periodic mechanical stress [13]. Increasing evidence suggests that PLC $\gamma 1$ activation elevates the levels of cytosolic $\mathrm{Ca}^{2+}$ by increasing calcium release from the endoplasmic reticulum $[14,15]$. Thus, we have reason to speculate that in chondrocytes, periodic mechanical stress-induced PLC $\gamma 1$ activation would induce the influx of intracellular $\mathrm{Ca}^{2+}$ that is responsible for the activation of CaMKII. Moreover, little is known about the specific functions of CaMKII in chondrocytes under periodic mechanical stress. Thus, in the current study, the activation of CaMKII, and final effects of CaMKII on chondrocyte proliferation and matrix synthesis in the context of periodic mechanical stress were examined.

Proline-rich tyrosine kinase 2 (Pyk2) is one member of the non-receptor protein kinases that are highly homologous to FAK and that participate in activation of the downstream signaling events $[16,17]$. Several researchers have confirmed that mechanical stimuli could activate FAK signals to modulate cell proliferation in various cell types including chondrocytes $[2,18,19]$. In addition, work from Boutahar and Sonomura have explored the theory that mechanical stimulation activates Pyk2 signaling in osteoblasts and renal tubular epithelial cells $[20,21]$. Furthermore, Pyk2 was identified to affect cell proliferation in several cell types in response to many different stimuli $[22,23]$. However, the special functions of Pyk2 in the process of mechanotransduced signal pathways in chondrocytes were completely unknown. Thus, elucidation of the roles of Pyk2 in mechanosensing, and in cell behavior and function in chondrocytes are essential under conditions of periodic mechanical stress.

In case of the involvement of CaMKII and Pyk2 in periodic mechanical stress-mediated chondrocyte proliferation and matrix synthesis, the questions then arose as to whether CaMKII and Pyk2 were associated with the integrin $\beta 1$-ERK1/2 signal cascade and the upstream and downstream relationships between CaMKII and Pyk2. ERK1/2 has been widely reported to be downstream of CaMKII and Pyk2 in many cell types under different conditions, and integrins also appear vital for the activation of CaMKII and Pyk2 in several different settings [24-27]. However, these may not be true for all cells. In addition, the relationships between CaMKII and Pyk2 remain enigmatic in chondrocytes subjected to periodic mechanical stress. Thus, the relationships between integrin $\beta 1$, CaMKII, Pyk2 and ERK1/2 in chondrocytes need to be established in this context.

In summary, we aimed to address the question of whether CaMKII and Pyk2 were implicated in the regulation of periodic mechanical stress-mediated cellular processes in chondrocytes, and to investigate the upstream and downstream relationships between integrin $\beta 1$, CaMKII, Pyk2 and ERK1/2 in this system, with a view to linking these signals into mitogenic cascades. 


\section{Cellular Physiology Cell Physiol Biochem 2017;42:383-396 and Biochemistry Published \begin{tabular}{l|l} 
DOI: 10.1159/000477483 & $\begin{array}{l}\text { C } 2017 \text { The Author(s). Published by S. Karger AG, Basel } \\
\text { www.karger.com/cpb }\end{array}$
\end{tabular} \\ Liang et al.: CaMKII-Mediated Pyk2 Signaling}

\section{Materials and Methods}

\section{Materials}

Two-week-old Sprague-Dawley (SD) rats of either sex were provided by the Animal Center of Nanjing Medical University. Fetal bovine serum was purchased from Hangzhou Sijiqing Biological Engineering Materials Co., Ltd. (Hangzhou, China). DMEM-F12, trypsin, collagenase II, and anti-collagen monoclonal antibody II were purchased from Gibco (Thermo Fisher Scientific, Waltham, MA, USA). Type II collagen was purchased from Sigma (St Louis, MO, USA). Cell Counting Kit-8 (CCK8) was purchased from Beyotime Institute of Biotechnology (Jiangsu, China). Anti-Pyk2, anti-phospho-Pyk2 (Tyr ${ }^{402}$ ), anti-ERK1/2, antiphospho-ERK1/2 (Thr ${ }^{202} / \mathrm{Tyr}^{204}$ ) and HRP-goat anti-rabbit IgG were supplied by Cell Signaling Technology (Danvers, MA, USA). Anti-CaMKII and anti-phospho-CaMKII $\left(\mathrm{Thr}^{286}\right.$ ) were supplied by Abcam (Cambridge, MA, USA). HRP-conjugated GAPDH antibody was supplied by Kang Chen Biotech (Shanghai, China). ECL was purchased from Amersham Biosciences (Chalfont St Giles, UK), KN-93and PF431396 were purchased from Biomol International (Enzo Life Sciences, Farmingdale, NY, USA). The blocking antibody against integrin $\beta 1$ was supplied by BD Biosciences (Franklin Lakes, NJ, USA). RNAiso Plus, PrimeScript RT Reagent Kit, and SYBR Premix Ex Taq II were purchased from TaKaRa Bio Inc. (Shiga, Japan). Pyk2shRNA (r) lentiviral particles, CaMKII shRNA (r) lentiviral particles, control shRNA lentiviral particles and polybrene were supplied by Santa Cruz Biotechnology (Santa Cruz, CA, USA).

A cell incubator (Heraeus BB 5060), air-tight cell culture device and reciprocating pressure pump, barrier type pressure transducer, and inversion microscope equipped with camera system were bought from Heraeus (Hanau, Germany), Taixing Experimental Instrument Factory (Jiangsu, China), Tianjin Plastics Research Institute (Tianjin, China), and Olympus (Tokyo, Japan), respectively.

\section{Methods}

Cell culture. Chondrocytes were harvested using the method described by Séguin and Bernier [28]. Cells were purified by repeated adherence, and morphology was observed under an inverted phase contrast microscope by staining collagen type II according to the conventional ABC method. Cells of the second generation were seeded onto glass slides ( $25 \mathrm{~mm} \times 25 \mathrm{~mm}$ ) coated with type II collagen at a density of $10^{5}$ cells. Experiments were performed when cells were approximately 70-80\% confluent.

Inhibitors. Blocking antibodies against integrin $\beta 1, \mathrm{KN}-93$ and PF431396 were specific inhibitors of integrin $\beta 1$, CaMKII and Pyk2, respectively. The blocking antibody against integrin $\beta 1$ was dissolved in DMEM, and the other inhibitors were dissolved in anhydrous dimethyl sulfoxide (DMSO) to form 1,000x concentrated solutions. Aliquots of all inhibitors were stored at $-20^{\circ} \mathrm{C}$. Each concentrated solution was diluted 1,000× immediately prior to use; KN-93 and PF431396 pretreatment groups contained 0.1\% (v/v) DMSO, which was the concentration used for the control group. Cells were pre-treated with KN-93 $(10 \mu \mathrm{M})$, PF431396 $(10 \mu \mathrm{M})$, or an equivalent amount of DMEM or DMSO $(0.1 \% \mathrm{v} / \mathrm{v})$ for $1 \mathrm{~h}$. The remaining cells were pre-treated with blocking antibodies against integrin $\beta 1(10 \mu \mathrm{g} / \mathrm{mL}$ for each) or an equivalent amount of DMEM for $5 \mathrm{~h}$.

Construction of a periodic mechanical stress field. A periodic stress field encompassing the perfusion culture system with adjustable stress intensity and frequency was constructed by connecting the reciprocating intensifier pump to the air-tight cell culture device through a barrier-type pressure transducer, as previously described [29]. Our previous study found that tissue-engineered cartilage exhibited the best quality when the rabbit chondrocytes underwent stress varying from $0 \mathrm{kPa}$ to $200 \mathrm{kPa}$ at $0.1 \mathrm{~Hz}$. Therefore, this pressure range $(0-200 \mathrm{kPa})$ and frequency $(0.1 \mathrm{~Hz})$ were used in the experiment.

Experimental groups. Two steps were undertaken in the experiment. In the first step, cells were divided into a non-pressure group and a pressure group. Cells were maintained under static conditions or periodic mechanical stress for $0,0.5,1$ or $2 \mathrm{~h}$ prior to western blot analysis. In the second step, cells were pretreated with blocking antibodies against integrin $\beta 1$ (10 $\mu \mathrm{g} / \mathrm{mL}$ for each), KN-93 (10 $\mu \mathrm{M})$, or PF431396 (10 $\mu \mathrm{M})$, or with shRNA targeted to CaMKII, Pyk2 or control scrambled shRNA. Cells were maintained under static conditions or periodic mechanical stress for $1 \mathrm{~h}$ prior to western blot analysis, for $8 \mathrm{~h}$ prior to qPCR analysis (aggrecan and type II collagen gene expression), and for $3 \mathrm{~d}$ ( $8 \mathrm{~h}$ per $\mathrm{d}$ mechanical stress) prior to direct cell counting or CCK-8 assay.

All groups of cells involved in the experiments were incubated at $37^{\circ} \mathrm{C}$ with $5 \% \mathrm{CO}_{2}$. 


\section{Cellular Physiology Cell Physiol Biochem 2017;42:383-396 \\ \begin{tabular}{l|l} 
and Biochemistry Published online: May 26, 2017 & $\begin{array}{l}\text { (c) } 2017 \text { The Author(s). Published by S. Karger AG, Basel } \\
\text { www.karger.com/cpb }\end{array}$ \\
\hline
\end{tabular} \\ Liang et al.: CaMKII-Mediated Pyk2 Signaling}

\section{Western blot analysis}

Total protein was prepared and western blot analyses were performed as previously described [3032]. Total protein was prepared using RIPA buffer and the Bradford assay was used to determine protein concentration. Protein samples were resolved by sodium dodecyl sulfate polyacrylamide gel electrophoresis (SDS-PAGE) and transferred to nitrocellulose membranes. Following blocking for $1 \mathrm{~h}$ with $5 \%$ milk in TBST, the membranes were incubated with antibodies (1:1,000 dilutions for three antibodies) overnight at $4^{\circ} \mathrm{C}$. Blots were then incubated with horseradish peroxidase-conjugated secondary antibody at ambient temperature for $1 \mathrm{~h}$ and the bands were detected with ECL. The results were scanned using a gel imaging system (UVP Ltd., Cambridge, UK) and measured using Gel-Pro Analyzer software (Media Cybernetics, Rockville, MD, US).

\section{Quantitative real-time PCR ( $q$ PCR) analysis}

Total RNA was extracted using RNAiso Plus and was reverse transcribed into cDNA with the PrimeScript RT Reagent Kit according to the manufacturer's protocol. qPCR analysis was performed with the LightCycler System (Roche Diagnostics, Basel, Switzerland) using SYBR Premix Ex Taq II as previously described $[33,34]$. The reaction was performed in a $20-\mu \mathrm{L}$ mixture containing $2 \mu \mathrm{L}$ of the above cDNA. Each cDNA sample was amplified using specific primers (Table 1; TaKaRa). The cycling conditions were a 30-s initial denaturation step at $95^{\circ} \mathrm{C}$ followed by 40 cycles at $95^{\circ} \mathrm{C}$ for $5 \mathrm{~s}$ and $60^{\circ} \mathrm{C}$ for $20 \mathrm{~s}$. Gene expression for $\mathrm{AGC}$ and Col2 was normalized against that for GAPDH.

\section{Proliferation studies}

Proliferation studies were assessed by two different methods: direct cell counting and CCK-8 assay.

\section{Direct cell counting}

Cells were trypsinized and counted as previously described [35]. Second generation chondrocytes were seeded onto glass slides $(25 \mathrm{~mm} \times 25 \mathrm{~mm})$ coated with type II collagen at a density of $10^{5}$ cells and were randomly divided into different groups. Each group included cells on six glass slides. Experiments were performed when cells had reached approximately $70-80 \%$ confluence. Chondrocytes were cultured for 3 days under non-pressure conditions or conditions of periodic mechanical stress for $8 \mathrm{~h}$ per day prior to direct cell counting. Cells were trypsinized and counted. Cell number was determined by counting cells from each glass slide independently. The experiments were repeated five times.

\section{CCK-8 assay}

Cell proliferation was determined by using CCK-8 solution according to the manufacturer's instructions as previously described [36, 37]. Cells were added to $10 \mu \mathrm{L}$ CCK-8 solution in each well of five 96-well plates $(\mathrm{n}=5)$ and incubated for $4 \mathrm{~h}$ at $37^{\circ} \mathrm{C}$. The absorbance of each well was finally determined at $450 \mathrm{~nm}$ using a microplate reader.

\section{Co-immunoprecipitation analysis}

Cells were lysed and immunoprecipitation analyses were carried out as previously described [20]. Lysates were clarified by centrifugation at 14,000 rpm for $20 \mathrm{~min}$. Supernatants were transferred to fresh tubes and protein concentration of lysates was determined using the Bradford assay. Immunoprecipitations were typically performed using 1-2 $\mathrm{mg}$ of cell lysate and $2 \mu \mathrm{g}$ of purified monoclonal antibodies for PYK2 and CaMKII. After incubation at $4^{\circ} \mathrm{C}$ on a rotating device for $2 \mathrm{~h}$, immune complexes were precipitated at $4^{\circ} \mathrm{C}$ overnight on a rotating device of protein A-sepharose.

Table 1. Primer sequences and product sizes used for real-time PCR

\begin{tabular}{|c|c|c|c|}
\hline Genes & Sequence of primers $\left(5^{\prime}-3^{\prime}\right)$ & $\mathrm{AS}(\mathrm{bp})$ & AT(degrees) \\
\hline & F GAAGTGATGCATGGCATTGAGG & & \\
\hline \multirow[t]{3}{*}{ Aggrecan } & & 146 & 60 \\
\hline & R ATGATGGCGCTGTTCTGAAGG & & \\
\hline & F GAGGGCAACAGCAGGTTCAC & & \\
\hline \multirow[t]{3}{*}{ Type II collagen } & & 95 & 60 \\
\hline & R TGTGATCGGTACTCGATGATGG & & \\
\hline & F GGCACAGTCAAGGCTGAGAATG & & \\
\hline \multirow[t]{2}{*}{ GAPDH } & & 143 & 60 \\
\hline & R ATGGTGGTGAAGACGCCAGTA & & \\
\hline
\end{tabular}




\section{Cellular Physiology Cell Physiol Biochem 2017;42:383-396 \begin{tabular}{ll|l} 
and Biochemistry Published online: May 26, 2017 & $\begin{array}{l}\text { C) 2017 The Author(s). Published by S. Karger AG, Basel } \\
\text { www.karger.com/cpb }\end{array}$ \\
\hline
\end{tabular} \\ Liang et al.: CaMKII-Mediated Pyk2 Signaling}

Immunoprecipitates were washed three times with lysis buffer, extracted in $2 \times$ SDS-PAGE sample buffer by boiling for $5 \mathrm{~min}$, electrophoresed by SDS-PAGE, and then analyzed by western blotting.

\section{Statistical analysis}

Statistical analyses were performed using SPSS 14.0 software (SPSS Inc., Chicago, IL, USA) and the results are expressed as the mean \pm standard deviation. Student's unpaired t-tests and one-way analysis of variance (ANOVA) followed by post-hoc Fisher's least significance difference (LSD) tests were used to determine the statistical significance. A $P$ value of 0.05 was considered to be significant.

\section{Results}

Effects of periodic mechanical stress on the expression and activation of Pyk2 and CaMKII

Our results showed that periodic mechanical stress markedly induced phosphorylation of Pyk2 at Tyr ${ }^{402}$ and CaMKII at $\mathrm{Thr}^{286}$ in chondrocytes in comparison to those cultured under static conditions $\left(P<0.05\right.$ for each, Fig. $\left.1, \mathrm{n}=5,{ }^{*}\right)$. In addition, the phosphorylation levels of CaMKII and Pyk2 were both increased at $0.5,1$ and $2 \mathrm{~h}$ compared to that at $0 \mathrm{~h}$ under periodic mechanical stress $(P<0.05$ for each, Fig. $1, n=5$, \#).

Effects of selective inhibitors of Pyk2 and CaMKII on cell proliferation and matrix synthesis in response to periodic mechanical stress

We then sought to determine whether Pyk2 and CaMKII are required for periodic mechanical stress-induced chondrocyte proliferation and matrix synthesis. We observed that compared with the control group, both Pyk2 inhibition with PF431396 and CaMKII inhibition with KN-93 prevented chondrocyte proliferation and matrix synthesis under conditions of periodic mechanical stress $(P<0.05$ for each, Fig. $2, \mathrm{n}=5)$.

Fig. 1. Effects of periodic mechanical stress on the expression and phosphorylation of CaMKII at $\mathrm{Thr}^{286}$ and Pyk2 at Tyr ${ }^{402}$. Rat chondrocytes were cultured for $0,0.5,1$ or $2 \mathrm{~h}$ with or without periodic mechanical stress. The expression and phosphorylation levels of CaMKII at $\mathrm{Thr}^{286}$ and Pyk2 at $\mathrm{Tyr}^{402}$ were analyzed by western blotting and the total quantity of CaMKII and Pyk2 served as the respective controls. Results are represented in the histogram. The images shown are representative western
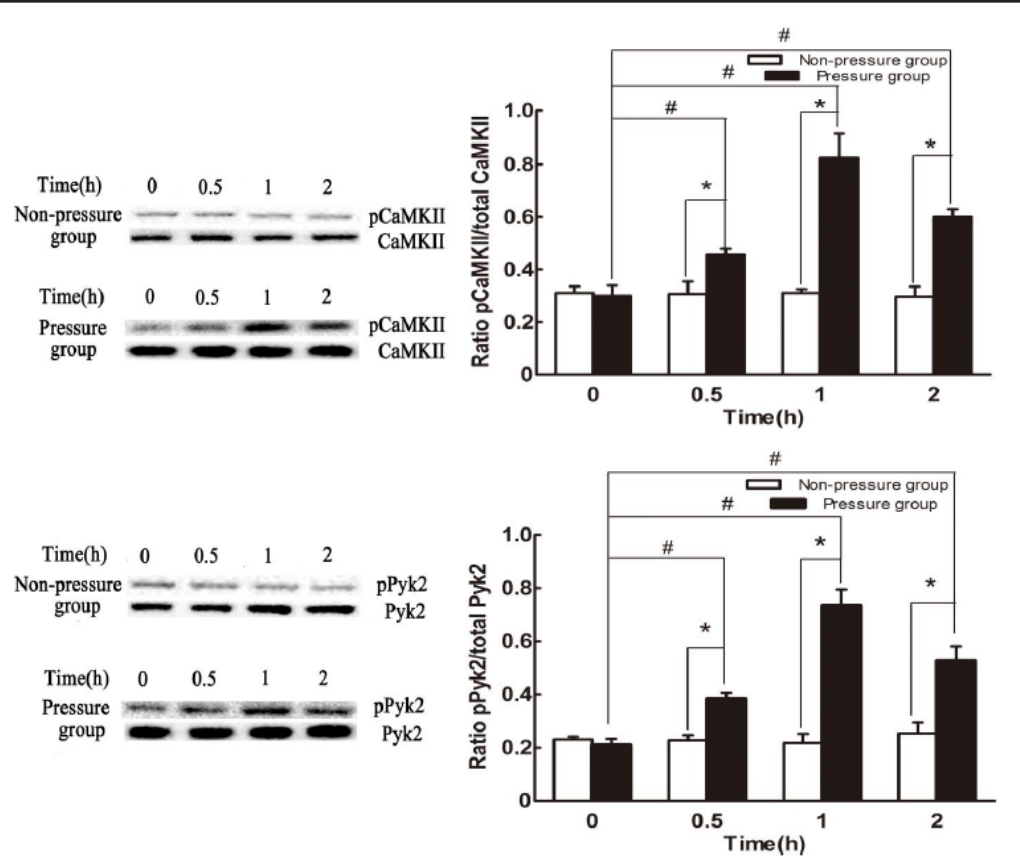

blotting results of five different experiments. The phosphorylation levels of CaMKII at Thr ${ }^{286}$ and Pyk2 at $\mathrm{Tyr}^{402}$ in the pressure groups were significantly increased compared to those in the non-pressure groups ( $\mathrm{n}=5,{ }^{*}, P<0.05$ for each, Student's unpaired t-test). The phosphorylation levels of CaMKII and Pyk2 were both increased at $0.5,1$ and $2 \mathrm{~h}$ in comparison to that at $0 \mathrm{~h}$ under periodic mechanical stress $(\mathrm{n}=5, \#, P<$ 0.05 for each, Student's unpaired t-test). 

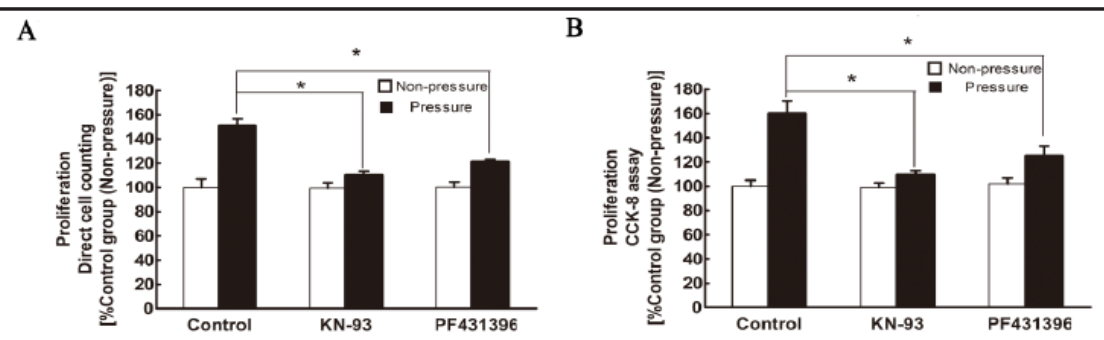

C

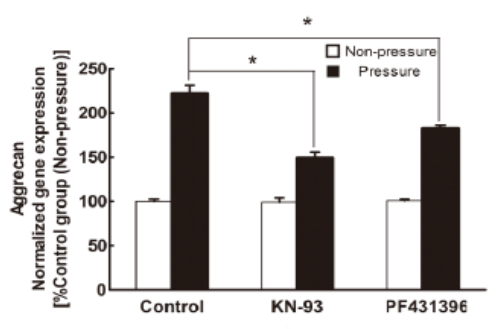

D



Fig. 2. Effects of KN-93 and PF431396 on chondrocyte proliferation and matrix synthesis in relation to periodic mechanical stress.After pretreatment with the CaMKII selective inhibitor KN-93, the Pyk2 selective inhibitor PF431396, or control vehicle (DMSO), rat chondrocytes were cultured for $3 \mathrm{~d}$ under static conditions or conditions of periodic mechanical stress for $8 \mathrm{~h}$ per day prior to proliferation studies, or chondrocytes were cultured for $8 \mathrm{~h}$ with or without periodic mechanical stress prior to matrix synthesis studies. Chondrocyte proliferation was analyzed using direct cell counting (A) and CCK-8 assay (B). Aggrecan (C) and type II collagen (D) gene expression levels were assessed using quantitative real-time PCR. Chondrocyte proliferation and gene expressions of aggrecan and type II collagen in KN-93 groups and PF431396 groups were both reduced in contrast to DMSO groups under periodic mechanical stress. ( $\mathrm{n}=5, P<0.05$ for each, analyzed by one-way analysis of variance [ANOVA] followed by post-hoc Fisher's least significant difference [LSD] test).

Effects of blockade of Pyk2 and CaMKII with targeted shRNA on periodic mechanical stress-stimulated chondrocyte proliferation and matrix synthesis

To determine whether Pyk2 and CaMKII are involved in periodic mechanical stressinduced chondrocyte proliferation and matrix synthesis, we pretreated chondrocytes with shRNA targeted to Pyk2, CaMKII and combined (Pyk2+ CaMKII) or non-targeting (NT) shRNA sequences for $48 \mathrm{~h}$. We observed that chondrocyte proliferation and matrix synthesis were both significantly inhibited in the Pyk2 targeted shRNA, CaMKII targeted shRNA and combined (Pyk2+ CaMKII) targeted shRNA groups, relative to that in the NT shRNA group ( $P$ $<0.05$ for each, Fig. $3, \mathrm{n}=5$ ).

CaMKII is essential for periodic mechanical stress-induced ERK1/2 activation

We further evaluated the participation of CaMKII in ERK1/2 stimulation in the setting of periodic mechanical stress. CaMKII reduction via pretreatment with either its selective inhibitor KN-93 or its targeted shRNA prevented ERK1/2 phosphorylation relative to those in the control groups cultured under periodic mechanical stress $(P<0.05$ for each, Fig. 4, n $=5$ ).

CaMKII modulates periodic mechanical stress-induced Pyk2phosphorylation

The protein phosphorylation levels of Pyk2 were examined and found to be significantly attenuated upon pretreatment with the inhibitor KN-93 and with shRNA targeted to CaMKII as compared to mock transfectants under periodic mechanical stress $(P<0.05$ for each, Fig. $4, \mathrm{n}=5$ ). Co-immunoprecipitation studies showed that in relation to periodic mechanical stress, the association between CaMKII and Pyk2 was not increased compared with those cultured under static conditions (Fig. 7). 


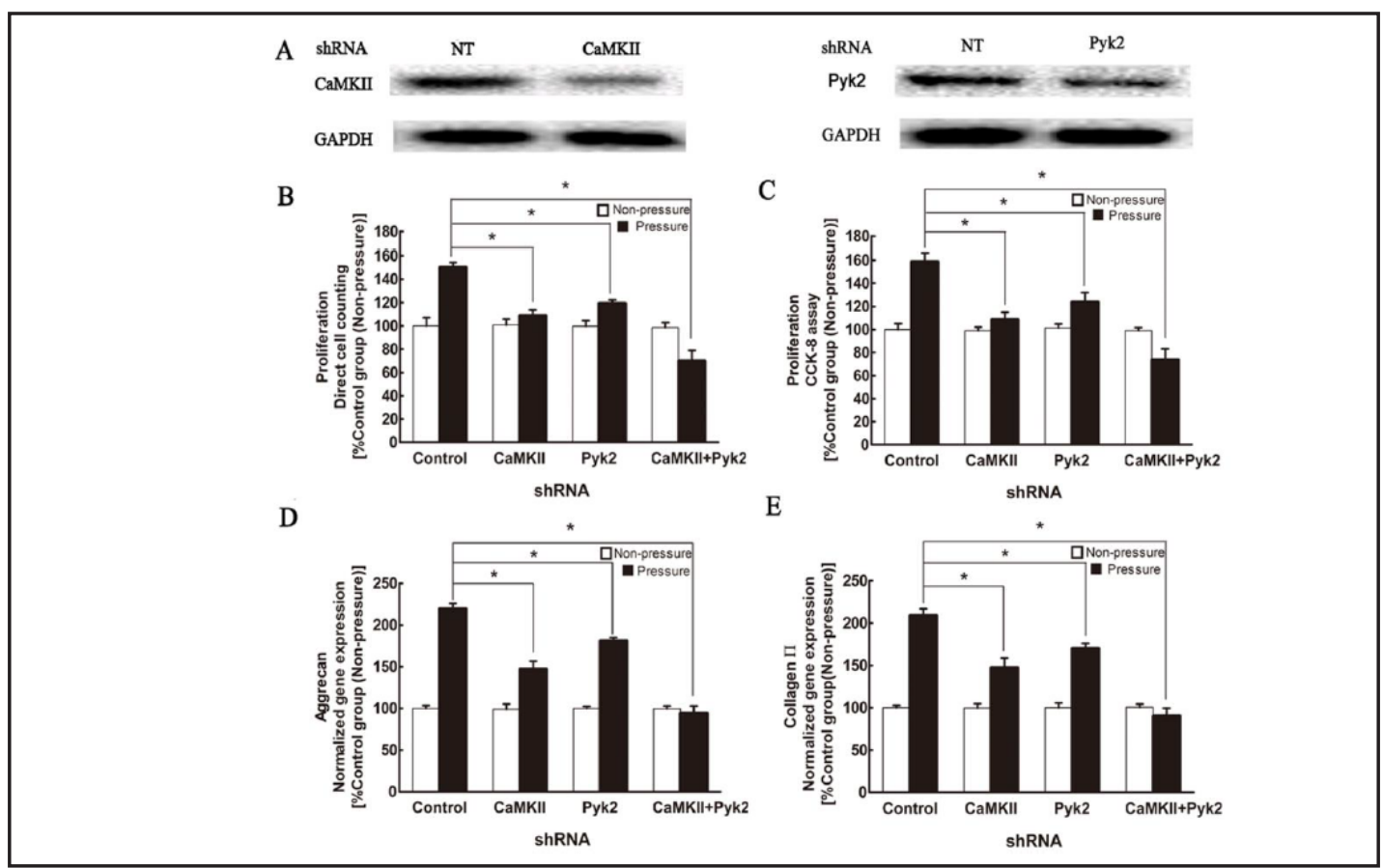

Fig. 3. Effects of CaMKII shRNA and Pyk2 shRNA on periodic mechanical stress-induced chondrocyte proliferation and matrix synthesis. Chondrocytes were transfected with shRNA targeted to CaMKII or Pyk2 or non-targeting (NT) sequences prior to lysis and western blotting for CaMKII and Pyk2 protein levels. The CaMKII or Pyk2 shRNA sequence achieved a $\sim 60 \%$ reduction in CaMKII protein level and a $52 \%$ reduction in Pyk2 protein level, respectively (A). After pretreatment with CaMKII shRNA, Pyk2 shRNA or the combination (CaMKII shRNA+ Pyk2 shRNA) or control shRNA, rat chondrocytes were cultured for $3 \mathrm{~d}$ under static conditions or conditions of periodic mechanical stress for $8 \mathrm{~h}$ per day prior to proliferation studies, or chondrocytes were cultured for $8 \mathrm{~h}$ with or without periodic mechanical stress prior to matrix synthesis studies. Cell proliferation was analyzed by direct cell counting (B) and CCK-8 assay (C). Aggrecan (D) and type II collagen (E) gene expression were measured by quantitative real-time PCR. Chondrocyte proliferation and gene expressions of aggrecan and type II collagen in Lv-shRNA-CaMKII groups, Lv-shRNA-Pyk2 groups and Lv-shRNA-(CaMKII+Pyk2) groups were all diminished in comparison with Lv-GFP groups under periodic mechanical stress. ( $n=5, P<0.05$ for each, analyzed by one-way analysis of variance [ANOVA] followed by post-hoc Fisher's least significant difference [LSD] test).

\section{Pyk2 is required for periodic mechanical stress-induced ERK1/2 activation}

The phosphorylation levels of ERK1/2 were noticeably reduced in the PF431396 and Pyk2-shRNA transfected groups subjected to periodic mechanical stress, in comparison with the control groups $(P<0.05$ for each, Fig. $5, \mathrm{n}=5)$.

CaMKII is not regulated by Pyk2 in response to periodic mechanical stress

Next, we aimed to investigate the role of Pyk2 in periodic mechanical stress-induced CaMKII phosphorylation. Under periodic mechanical stress, CaMKII activation was not affected by pretreatment of chondrocytes with PF431396 or with shRNA targeted to Pyk2 ( $P$ $<0.05$ for each, Fig. $5, \mathrm{n}=5$ ).

Integrin $\beta 1$ inhibition suppressed the phosphorylation levels of CaMKII and Pyk2 under periodic mechanical stress

Pretreatment with blocking antibodies against integrin $\beta 1$ markedly reduced periodic mechanical stress-induced CaMKII and Pyk2 phosphorylation in comparison to the control groups $(P<0.05$ for each, Fig. 6, $\mathrm{n}=5)$.

\section{KARGER}




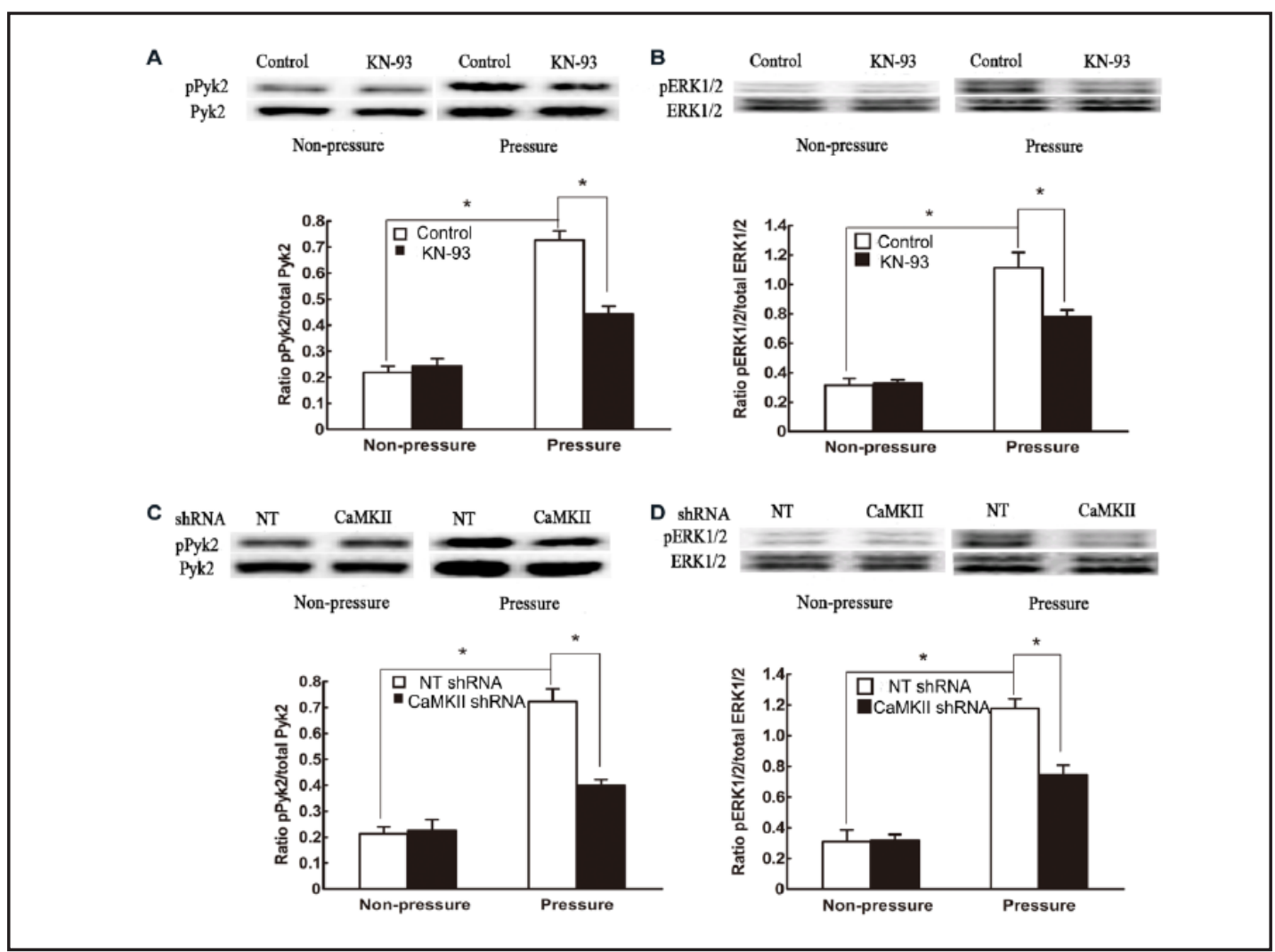

Fig. 4. Effects of KN-93 and CaMKII shRNA on the expression and phosphorylation of Pyk2 and ERK1/2 under conditions of periodic mechanical stress. After pretreatment with DMSO or the CaMKII inhibitor KN93, or CaMKII shRNA or non-targeting (NT) sequence, rat chondrocytes were cultured for $1 \mathrm{~h}$ under static conditions or conditions of periodic mechanical stress. The expression and phosphorylation levels of Pyk2 $(A, C)$, and ERK1/2 (B, D) were analyzed by western blotting. The total amounts of Pyk2 and ERK1/2 served as respective controls. The images shown are representative western blotting results of five different experiments. The phosphorylation levels of Pyk2-Tyr402 and ERK1/2- Thr202/Tyr204 in the KN-93 and CaMKII shRNA groups were significantly reduced compared to those in the control groups in chondrocytes subjected to periodic mechanical stress ( $\mathrm{n}=5$, $* \mathrm{P}<0.05$, Student's unpaired $\mathrm{t}$-test). The activation of Pyk2 and ERK1/2 were markedly increased in control pressure groups in comparison to those in control non-pressure groups ( $\mathrm{n}=5,{ }^{*} \mathrm{P}<0.05$, Student's unpaired t-test).

\section{Discussion}

In the current study, we observed that application of periodic mechanical stress to chondrocytes induced integrin $\beta 1$ activation, leading to the activation of CaMKII phosphorylation at $\mathrm{Thr}^{286}$ and Pyk2 phosphorylation at $\mathrm{Thr}^{402}$, and subsequently the phosphorylation of ERK1/2, which is ultimately responsible for the up-regulation of chondrocyte proliferation and matrix synthesis.

Previous studies regarding CaMKII in the nervous system and heart have resulted in its functions being well characterized [38-40]. Accumulated evidence has shown that CaMKII activation is closely related to increased intracellular calcium levels [8, 9]. In addition, PLC $\gamma 1$ signaling has also been proven to facilitate the influx of intracellular $\mathrm{Ca}^{2+}[14,15]$. Thus, PLC $\gamma 1$ may be located upstream of CaMKII by influencing intracellular calcium levels in some cases. Indeed, PLC $\gamma 1$ activation has been reported to activate CaMKII signaling in the study of mouse embryonic fibroblasts and human breast cancer cells [41, 42]. As PLC $\gamma 1$ has been proven to be a critical determinant in periodic mechanical stress-induced chondrocyte proliferation and matrix synthesis, we examined the specific roles of CaMKII in 


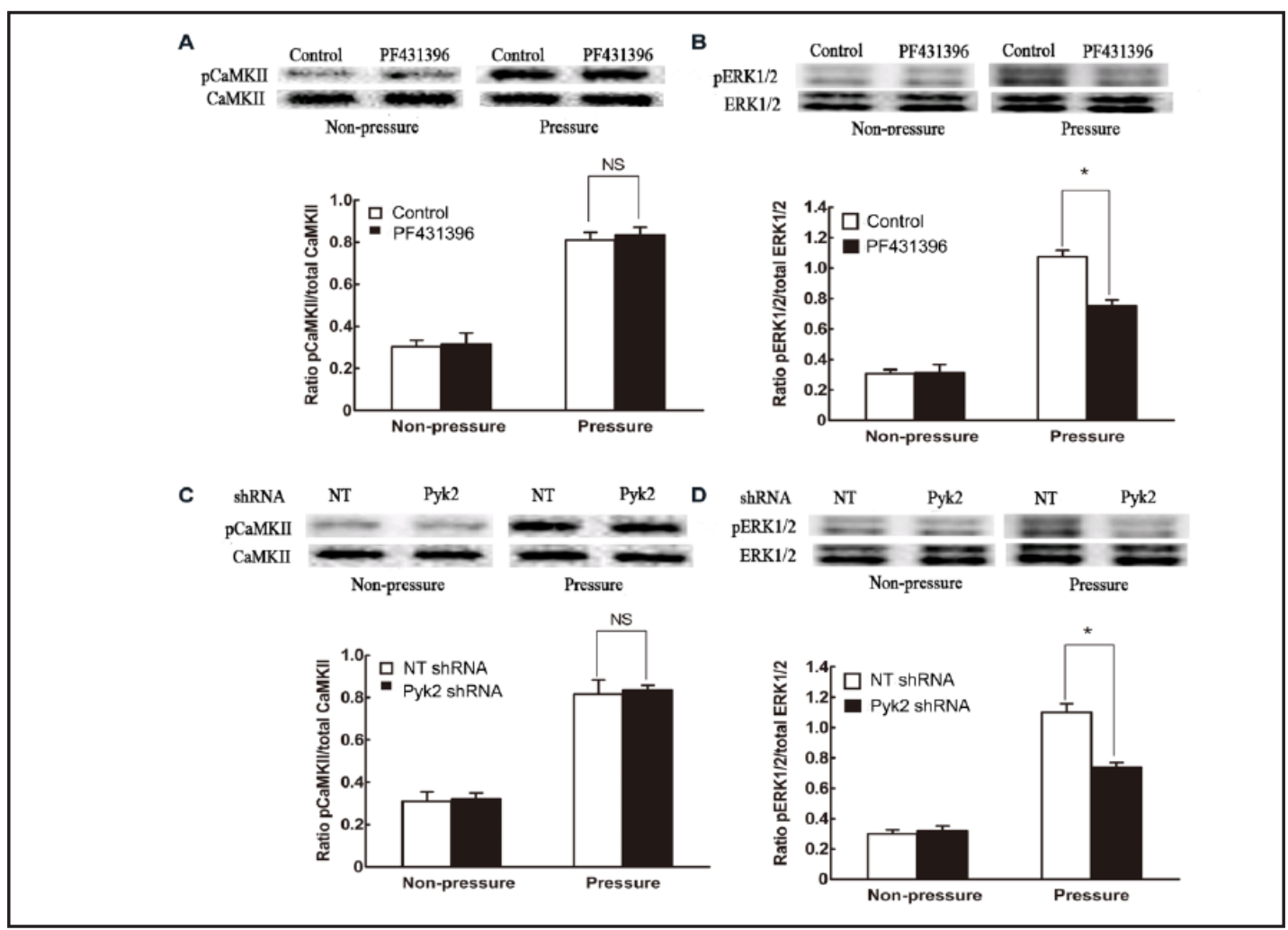

Fig. 5. Effects of PF431396 and Pyk2 shRNA on the expression and phosphorylation of CaMKII and ERK1/2 under conditions of periodic mechanical stress. After pretreatment with DMSO or the Pyk2 inhibitor PF431396, or Pyk2 shRNA or non-targeting (NT) sequence, rat chondrocytes were cultured for $1 \mathrm{~h}$ under static conditions or conditions of periodic mechanical stress. The expression and phosphorylation levels of CaMKII (A, C), and ERK1/2 (B, D) were analyzed by western blotting. The total amounts of CaMKII and ERK1/2 served as respective controls. The images shown are representative western blotting results of five different experiments. The phosphorylation levels of ERK1/2- Thr202/Tyr204 in the PF431396 and Pyk2 shRNA groups were significantly reduced compared to those in the control groups in chondrocytes subjected to periodic mechanical stress $\left(n=5,{ }^{*} P<0.05\right.$, Student's unpaired t-test), while the activation of CaMKII-Thr286 in the PF431396 and the Pyk2 shRNA groups was not affected ( $=5, P>0.05$ for each, Student's unpaired t-test).

chondrocytes under periodic mechanical stress. We found that periodic mechanical stress significantly enhanced the phosphorylation levels of CaMKII at $\mathrm{Thr}^{286}$, in comparison with that in chondrocytes cultured under static conditions. Following blocking CaMKII with KN93 or shRNA targeted to CaMKII, we observed that chondrocyte proliferation and matrix synthesis were strongly attenuated even after exposure to periodic mechanical stress. Our results strongly demonstrated that CaMKII seems to play an essential role in chondrocytic adaptation and response to periodic mechanical stress. Several lines of evidence revealed that in some other cell types including osteoblasts and cardiomyocytes, CaMKII signaling was also confirmed to be indispensable in mechanosensing and signaling in cells subjected to physical forces $[43,44]$. To our knowledge, the results are the first to analyze the effects of CaMKII signaling on chondrocyte mitogenic effects in relation to periodic mechanical stress.

Although Pyk2 protein is highly homologous to FAK, their activation patterns appear to vary among settings and cell types $[45,46]$. For example, Loeser et al. demonstrated that in response to fibronectin fragments, the phosphorylation levels of Pyk2 were significantly increased, while FAK activation was not affected in human chondrocytes [45]. However, work from Sugimura et al. showed that in tissues of the rat proximal aorta, either FAK or Pyk2 was activated by elevated blood pressure [46]. FAK has been reported to be involved in periodic 


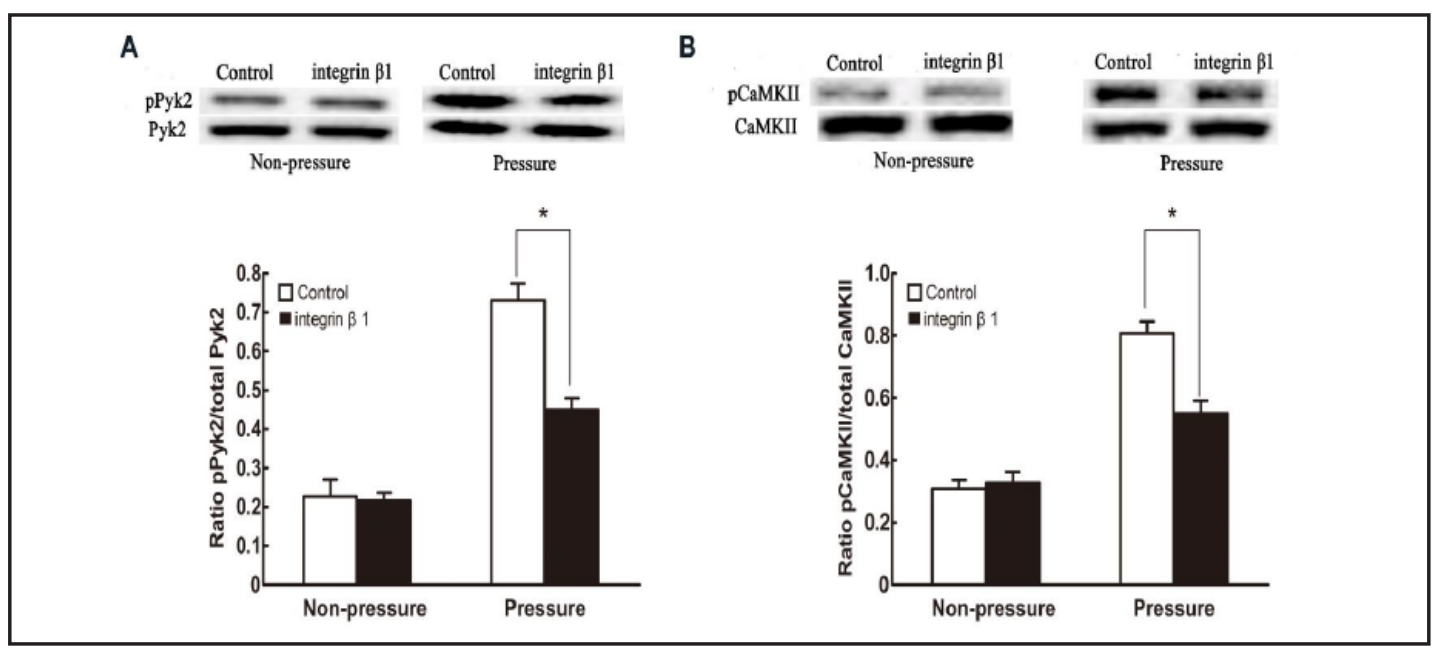

Fig. 6. Effects of integrin $\beta 1$ on the expression and phosphorylation of CaMKII and Pyk2 under conditions of periodic mechanical stress. After pretreatment with control vehicle (DMEM) or blocking antibody against integrin $\beta 1$, rat chondrocytes were cultured for $1 \mathrm{~h}$ under static conditions or conditions of periodic mechanical stress. The expression and phosphorylation levels of Pyk2 (A), and CaMKII (B) were analyzed by western blotting. The total amounts of Pyk2 and CaMKII served as respective controls. The images shown are representative western blotting results of five different experiments. Upon pretreatment with blocking antibody against integrin $\beta 1$, the phosphorylation levels of Pyk2-Tyr402 and CaMKII-Thr286 were significantly reduced in comparison to the control groups in chondrocytes under periodic mechanical stress ( $\mathrm{n}=$ $5,{ }^{*} \mathrm{P}<0.05$, Student's unpaired t-test).

mechanical stress-induced chondrocyte proliferation and matrix synthesis [2]. However, to date, the roles of Pyk2 in mechanical-stimulated signaling in chondrocytes remain elusive. We found that periodic mechanical stress leads to Pyk2-Tyr ${ }^{402}$ activity in chondrocytes. Moreover, Pyk2 reduction with shRNA or its selective inhibitor PF431396 significantly prevented periodic mechanical stress-stimulated chondrocyte proliferation and matrix synthesis. Therefore, in addition to FAK, Pyk2 phosphorylation at $\mathrm{Tyr}^{402}$ also appears central to the cellular biological effects in chondrocytes, in the context of periodic mechanical stress. Our data are in agreement with those of a study on osteoblast mechanotransduction, by Boutahar et al. who reported that in response to cyclic strain, ERK2 activation-induced osteoblast proliferation was both FAK- and Pyk2-dependent [20]. Interestingly, work from Young et al. showed that in the same cell type (osteoblasts), only FAK was required for fluid shear stress-induced osteoblast mechanotransduction [47]. This discrepancy in the results may reflect differences in cell types and mechanical stimuli applied during mechanotransduction. In any case, it is a novel finding that Pyk2 regulates periodic mechanical stress-mediated chondrocyte proliferation and matrix synthesis.

As we have proved that integrin $\beta 1$-initiated ERK1/2 signaling is involved in periodic mechanical stress-induced cellular response in our previous study, and probed the participation of CaMKII and Pyk2 in the current study, one concern might be raised: there may be some upstream and downstream relationships between integrin $\beta 1$, CaMKII, Pyk2 and ERK1/2. ERK1/2 has often been indicated to be a downstream molecular mediator of CaMKII and Pyk2 in many other cell types [24,25]. In our experiments, either pretreatment of chondrocytes with the CaMKII inhibitor KN-93 and shRNA targeted to CaMKII or the Pyk2 inhibitor PF 431396 and shRNA targeted to Pyk2 abolished ERK1/2 activation under periodic mechanical stress, which suggests that ERK1/2 is located downstream of CaMKII and Pyk2 in this context. Similarly, in an earlier study in osteoblasts, Boutahar et al. demonstrated that activated Pyk2 played a pivotal role in cyclic strain-induced ERK1/2 activation [20]. In contrast, Fukuno et al. demonstrated that stretching enhanced the expression levels of IL-6 in osteoblasts through the JNK and p38 pathways [44]. Our results indicate that in 


\section{Cellular Physiology Cell Physiol Biochem 2017;42:383-396 \begin{tabular}{l|l|l} 
DOI: 10.1159/000477483 & & $\begin{array}{l}\text { O } 2017 \text { The Author(s). Published by S. Karger AG, Basel } \\
\text { www.karger.com/cpb }\end{array}$ \\
\hline
\end{tabular} \\ Liang et al.: CaMKII-Mediated Pyk2 Signaling}

Fig. 7. The association between CaMKII and Pyk2 subjected to periodic mechanical stress. After being subjected to periodic mechanical stress or cultured under static conditions for $0,0.5,1$ or $2 \mathrm{~h}$, rat chondrocytes were lysed immediately. Lysates were immuno-precipitated using an anti-PYK2 antibody (Anti PYK2 IP). The immune complexes were then subjected to western blotting and probed with an anti-CaMKII antibody (Anti- CaMKII IB).

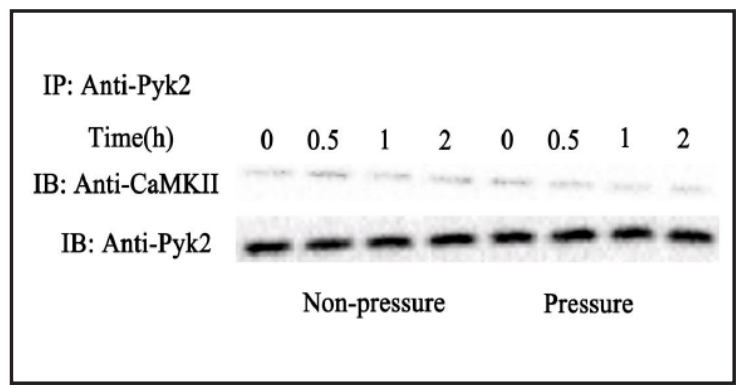

chondrocytes, when subjected to periodic mechanical stress, ERK1/2 activation is at least partly mediated by CaMKII and Pyk2, and could not exclude the participation of other signal proteins located downstream of CaMKII and Pyk2.

Increasing evidence has confirmed that the activation of both CaMKII and Pyk2 are closely related to the functions of integrins in many cell types [26, 27]. We observed that blocking integrin $\beta 1$ with its functional blocking antibody significantly abrogated phosphorylation of Pyk2 at Tyr ${ }^{402}$ and CaMKII at $\mathrm{Thr}^{286}$ in chondrocytes in the application of periodic mechanical stress. Our results clearly illustrated that integrin $\beta 1$ activation played essential roles in periodic mechanical stress-facilitated CaMKII signaling and Pyk2 signaling in chondrocytes.

Next, we aimed to investigate the interactions between CaMKII and Pyk2. In addition to CaMKII, Pyk2 has also been found to be a calcium-dependent tyrosine kinase in a variety of signaling pathways $[48,49]$. Thus, we have reason to explore whether there could be some causal relationship between periodic mechanical stress-induced CaMKII activation and Pyk2 activation. A search of the literature revealed no studies about the interactions between CaMKII and Pyk2 under conditions of mechanical stimulation. In response to some non-mechanical stimuli, CaMKII has been considered to be an upstream regulator of Pyk2 in several cell types [50-52]. Unexpectedly, Xie and colleagues reported that CaMKII inhibition with KN62 was unable to block GnRHa-induced Pyk2 phosphorylation in $\alpha \mathrm{T} 3-1$ cells [53]. We observed that under periodic mechanical stress, CaMKII reduction significantly disrupted the phosphorylation of Pyk2, whereas the activation of CaMKII was not affected after Pyk2 inhibition, which suggested that Pyk2 was located downstream of CaMKII in our experiments. Taken together, the differences between these reports and our results may be due to the activation of CaMKII and Pyk2 by multiple inputs and variations in cell types and settings. We further used co-immunoprecipitation analyses to explore the exact mechanisms by which CaMKII leads to activation of Pyk2. We found that periodic mechanical stress was unable to increase the association between CaMKII and Pyk2, which suggests that CaMKII and Pyk2 may act via other substrates proximal to Pyk2 rather than acting directly.

Above all, we have identified CaMKII and Pyk2 to be two remarkable signal proteins involved in the periodic mechanical stress-initiated integrin $\beta 1$-ERK1/2 signal cascade. Integrin $\beta 1$ can recruit and activate Pyk2, which requires activation of CaMKII, which, in turn, facilitates activation of ERK1/2 in chondrocytes under periodic mechanical stress. Briefly, periodic mechanical stress promotes chondrocyte proliferation and matrix synthesis through the integrin $\beta 1-C a M K I I-P y k 2-E R K 1 / 2$ pathway.

\section{Abbreviations}

CaMKII $\left(\mathrm{Ca}^{2+} /\right.$ calmodulin-dependent protein kinase II); PYK2 (proline-rich tyrosine kinase); FAK (focal adhesion kinase); ERK (extracellular signal-regulated kinase); JNK (c-Jun N-terminal kinase); DMEM (Dulbecco's modified Eagle's medium); HRP (Horseradish Peroxidase). 


\section{Cellular Physiology Cell Physiol Biochem 2017;42:383-396 \begin{tabular}{l|l} 
DOI: 10.1159/000477483 & $\begin{array}{l}\text { O 2017 The Author(s). Published by S. Karger AG, Basel } \\
\text { www.karger.com/cpb }\end{array}$
\end{tabular} \\ Liang et al.: CaMKII-Mediated Pyk2 Signaling}

\section{Acknowledgements}

This work was supported by the National Natural Science Foundation (grant No.: 81601897)

\section{Disclosure Statement}

The authors declare no competing interests.

\section{References}

1 Ren K, Liu F, Huang Y, Liang W, Cui W, Wang Q, Fan W: Periodic mechanical stress activates integrinbeta1dependent src-dependent plcgamma1-independent rac1 mitogenic signal in rat chondrocytes through erk1/2. Cell Physiol Biochem 2012;30:827-842.

- Liang W, Ren K, Liu F, Cui W, Wang Q, Chen Z, Fan W: Periodic mechanical stress stimulates the FAK mitogenic signal in rat chondrocytes through ERK1/2 activity. Cell Physiol Biochem 2013;32:915-930.

-3 Liang W, Zhu C, Liu F, Cui W, Wang Q Chen Z, Zhou Q, Xu S, Zhai C, Fan W: Integrin $\beta 1$ Gene Therapy Enhances in Vitro Creation of Tissue-Engineered Cartilage Under Periodic Mechanical Stress. Cell Physiol Biochem 2015;37:1301-1314.

-4 Song H, Liang W, Xu S, Li Z, Chen Z, Cui W, Zhou J, Wang Q, Liu F, Fan W: A novel role for integrin-linked kinase in periodic mechanical stress-mediated ERK1/2 mitogenic signaling in rat chondrocytes. Cell Biol Int 2016;40:832-839.

-5 Popov C, Burggraf M, Kreja L, Ignatius A, Schieker M, Docheva D: Mechanical stimulation of human tendon stem/progenitor cells results in upregulation of matrix proteins, integrins and MMPs, and activation of p38 and ERK1/2 kinases. BMC Mol Biol 2015;16:6.

6 Shih YR, Tseng KF, Lai HY,Lin CH,LeeOK: Matrix stiffness regulation of integrin-mediated mechanotransduction during osteogenic differentiation of human mesenchymal stem cells. J Bone Miner Res 2011;26:730-738.

7 Cheng M, Guan X, Li H, Cui X, Zhang X, Li X, Jing X, Wu H, Avsar E: Shear stress regulates late EPC differentiation via mechanosensitive molecule-mediated cytoskeletal rearrangement. PLoS One 2013;8:e67675.

-8 Winters CJ, Koval O, Murthy S, Allamargot C, Sebag SC, Paschke JD, JafferOA, Carter AB, Grumbach IM: CaMKII inhibition in type II pneumocytes protects from bleomycin-induced pulmonary fibrosis by preventing Ca2+dependent apoptosis. Am J Physiol Lung Cell Mol Physiol 2016;310:L86-94.

-9 Lv X, Guo F, Xu X, Chen Z, Sun X, Min D, Cao Y, Shi X, Wang L, Chen T,Shaw C, Gao H, Hao L, Cai J: Abnormal alterations in the $\mathrm{Ca}^{2+} / \mathrm{CaV} 1.2 /$ calmodulin/caMKII signaling pathway in a tremor rat model and incultured hippocampal neurons exposed to $\mathrm{Mg}^{2}$-free solution. Mol Med Rep 2015;12:6663-6671.

- 10 Saddouk FZ, Sun LY, Liu YF, Jiang M, Singer DV, Backs J, Van Riper D, Ginnan R, Schwarz JJ, Singer HA: Ca2+/ calmodulin-dependent protein kinase II- $\gamma$ (CaMKII $\gamma$ ) negatively regulates vascular smooth muscle cell proliferation and vascular remodeling. FASEB J 2016;30:1051-1064.

11 Ampem PT, Smedlund K, Vazquez G: Pharmacological evidence for a role of the transient receptor potential canonical 3 (TRPC3) channel in endoplasmic reticulum stress-induced apoptosis of human coronary artery endothelial cells. Vascul Pharmacol 2016;76:42-52.

12 Umemura M, Baljinnyam E, Feske S, De Lorenzo MS, Xie LH, Feng X, Oda K, Makino A, Fujita T, Yokoyama U, Iwatsubo M, Chen S, Goydos JS, Ishikawa Y, Iwatsubo K: Store-operated Ca2+ entry (SOCE) regulates melanoma proliferation and cell migration. PLoS One 2014;9:e89292.

13 Ren K, Ma Y, Huang Y, Liang W, Liu F, Wang Q Cui W, Liu Z, Yin G, Fan W: Periodic mechanical stress activates MEK1/2-ERK1/2 mitogenic signals in rat chondrocytes through Src and PLC $\gamma 1$. Braz J Med Biol Res 2011;44:1231-1242.

14 Wei L, Lu N, Dai Q, Rong J, Chen Y, Li Z, You Q, Guo Q: Different apoptotic effects of wogonin via induction of $\mathrm{H}(2) \mathrm{O}(2)$ generation and $\mathrm{Ca}(2+)$ overload in malignant hepatoma and normal hepatic cells. J Cell Biochem 2010;111:1629-1641.

15 Zhou X, Yang W, Li J: Ca2+- and protein kinase C-dependent signaling pathway for nuclear factor-kappaB activation, inducible nitric-oxide synthase expression, and tumor necrosis factor-alpha production in 


\section{Cellular Physiology Cell Physiol Biochem 2017;42:383-396 \begin{tabular}{l|l} 
DOI: 10.1159/000477483 & $\begin{array}{l}\text { O 2017 The Author(s). Published by S. Karger AG, Basel } \\
\text { www.karger.com/cpb }\end{array}$
\end{tabular} \\ Liang et al.: CaMKII-Mediated Pyk2 Signaling}

lipopolysaccharide-stimulated rat peritoneal macrophages. J Biol Chem 2006;281:31337-31347.

- 16 Iiizumi M, Bandyopadhyay S, Pai SK, Watabe M, Hirota S, Hosobe S, Tsukada T, Miura K, Saito K, Furuta E, Liu W, Xing F, Okuda H, Kobayashi A, Watabe K: RhoC promotes metastasis via activation of the Pyk2 pathway in prostate cancer. Cancer Res 2008;68:7613-7620.

17 Vanarotti MS, Finkelstein DB, Guibao CD, Nourse A, Miller DJ, Zheng JJ: Structural Basis for the Interaction between Pyk2-FAT Domain and Leupaxin LD Repeats. Biochemistry 2016;55:1332-1345.

$\checkmark 18$ Lee DY, Li YS, Chang SF, Zhou J, Ho HM, Chiu JJ, Chien S: Oscillatory flow-induced proliferation of osteoblastlike cells is mediated by alphavbeta3 and beta1 integrins through synergistic interactions of focal adhesion kinase and Shc with phosphatidylinositol 3-kinase and the Akt/mTOR/p70S6K pathway. J Biol Chem 2010;285:30-42.

19 Guo F, Carter DE, Leask A: Mechanical tension increases CCN2/CTGF expression and proliferation in gingival fibroblasts via a TGF $\beta$-dependent mechanism. PLoS One 2011;6:e19756.

20 Boutahar N, Guignandon A, Vico L, Lafage-Proust MH: Mechanical strain on osteoblasts activates autophosphorylation of focal adhesion kinase and proline-rich tyrosine kinase 2 tyrosine sites involved in ERK activation. J Biol Chem 2004;279:30588-30599.

-21 Sonomura K, Okigaki M, Kimura T, Matsuoka E, Shiotsu Y, Adachi T, Kado H, Ishida R, Kusaba T, Matsubara H, Mori Y: The kinase Pyk2 is involved in renal fibrosis by means of mechanical stretch-induced growth factor expression in renal tubules. Kidney Int 2012;81:449-457.

-22 Bijli KM, Kang BY, Sutliff RL, Hart CM: Proline-rich tyrosine kinase 2 downregulates peroxisome proliferatoractivated receptor gamma to promote hypoxia-induced pulmonary artery smooth muscle cell proliferation. Pulm Circ 2016;6:202-210.

23 Kacena MA, Eleniste PP, Cheng YH, Huang S, Shivanna M, Meijome TE, Mayo LD, Bruzzaniti A: Megakaryocytes regulate expression of Pyk2 isoforms and caspase-mediated cleavage of actin in osteoblasts. J Biol Chem 2012;287:17257-17268.

24 Raka F, Di Sebastiano AR, Kulhawy SC, Ribeiro FM, Godin CM, Caetano FA, Angers S, Ferguson SS: Ca(2+)/ calmodulin-dependent protein kinase II interacts with group I metabotropic glutamate and facilitates receptor endocytosis and ERK1/2 signaling: role of $\beta$-amyloid. Mol Brain 2015;8:21.

-25 Bhattachariya A, Turczyńska KM, Grossi M, Nordström I, Buckbinder L, Albinsson S, Hellstrand P: PYK2 selectively mediates signals for growth versus differentiation in response to stretch of spontaneously active vascular smooth muscle. Physiol Rep 2014;2. pii: e12080.

26 Shi Y, Ethell IM: Integrins control dendritic spine plasticity in hippocampal neurons through NMDA receptor and $\mathrm{Ca} 2+$ /calmodulin-dependent protein kinase II-mediated actin reorganization. J Neurosci 2006;26:18131822.

27 Kim S, Cipolla L, Guidetti G, Okigaki M, Jin J, Torti M, Kunapuli SP: Distinct role of Pyk2 in mediating thromboxane generation downstream of both G12/13 and integrin $\alpha \mathrm{IIb} \beta 3$ in platelets. J Biol Chem 2013;288:18194-18203.

-28 Seguin CA, Bernier SM: Tnfalpha suppresses link protein and type ii collagen expression in chondrocytes: Role of mek1/2 and nf-kappab signaling pathways. J Cell Physiol 2003;197:356-369.

-29 Nong L, Yin G, Ren K, Tang J, Fan W: Periodic mechanical stress enhances rat chondrocyte area expansion and migration through src-plcgamma1-erk1/2 signaling. Eur J Cell Biol 2010;89:705-711.

30 Wang P, Cao X, Nagel DJ, Yin G: Activation of ask1 during reperfusion of ischemic spinal cord. Neurosci Lett 2007;415:248-252.

- 31 Chen B, Huang Z, Zhang Y, Chen Y, Li Z: MicroRNA-145 Suppresses Osteosarcoma Metastasis via Targeting MMP16. Cell Physiol Biochem 2015;37:2183-2193.

- 32 Zhou X, Ye F, Yin C, Zhuang Y, Yue G, Zhang G: The Interaction Between MiR-141 and IncRNA-H19 in Regulating Cell Proliferation and Migration in Gastric Cancer. Cell Physiol Biochem 2015;36:1440-1452.

-33 Kloesch B, Liszt M, Steiner G, Broll J: Inhibitors of p38 and erk1/2 mapkinase and hydrogen sulphide block constitutive and il-1beta-induced il-6 and il-8 expression in the human chondrocyte cell line c-28/i2. Rheumatol Int 2012;32:729-736.

34 Gao F, Sun X, Wang L, Tang S, Yan C: Downregulation of MicroRNA-145 Caused by Hepatitis B Virus X Protein Promotes Expression of CUL5 and Contributes to Pathogenesis of Hepatitis B Virus-Associated Hepatocellular Carcinoma. Cell Physiol Biochem 2015;37:1547-1559.

-35 Chaturvedi LS, Marsh HM, Shang X, Zheng Y, Basson MD: Repetitive deformation activates focal adhesion kinase and erk mitogenic signals in human caco-2 intestinal epithelial cells through src and rac1. J Biol Chem 


\section{Cellular Physiology Cell Physiol Biochem 2017;42:383-396 \begin{tabular}{ll|l} 
and Biochemistry Published onlıne: May 26, 2017 & $\begin{array}{l}\text { C } 2017 \text { The Author(s). Published by S. Karger AG, Basel } \\
\text { www.karger.com/cpb }\end{array}$ \\
\hline
\end{tabular} \\ Liang et al.: CaMKII-Mediated Pyk2 Signaling}

2007;282:14-28.

-36 Bae JY, Han DW, Wakitani S, Nawata M, Hyon SH: Biological and biomechanical evaluations of osteochondral allografts preserved in cold storage solution containing epigallocatechin gallate. Cell Transplant 2010;19:681689.

-37 Zhi X, Tao J, Xiang G, Cao H, Liu Z, Yang K, Lv C, Ni S: APRIL induces cisplatin resistance in gastric cancer cells via activation of the NF- $\kappa B$ pathway. Cell Physiol Biochem 2015;35:571-585.

38 Hegyi B, Chen-Izu Y, Jian Z, Shimkunas R, Izu LT, Banyasz T: KN-93 inhibits IKr in mammalian cardiomyocytes. J Mol Cell Cardiol 2015;89(Pt B):173-176.

- 39 Jia M, Liu WX, Sun HL, Chang YQ Yang JJ, Ji MH, Yang JJ, Feng CZ: Suberoylanilide hydroxamic acid, a histone deacetylase inhibitor, attenuates postoperative cognitive dysfunction in aging mice. Front Mol Neurosci 2015;8:52.

-40 Capel RA, Bolton EL, Lin WK, Aston D, Wang Y, Liu W, Wang X, Burton RA, Bloor-Young D, Shade KT, Ruas M, Parrington J, Churchill GC, Lei M, Galione A, Terrar DA: Two-pore Channels (TPC2s) and Nicotinic Acid Adenine Dinucleotide Phosphate (NAADP) at Lysosomal-Sarcoplasmic Reticular Junctions Contribute to Acute and Chronic $\beta$-Adrenoceptor Signaling in the Heart. J Biol Chem 2015;290:30087-30098.

41 Kim HS, Lim JM, Kim JY, Kim Y, Park S, Sohn J: Panaxydol, a component of Panax ginseng, induces apoptosis in cancer cells through EGFR activation and ER stress and inhibits tumor growth in mouse models. Int J Cancer 2016;138:1432-1441.

42 Lundgren TK, Nakahata K, Fritz N, Rebellato P, Zhang S, Uhlén P: RET PLC $\gamma$ phosphotyrosine binding domain regulates Ca2+ signaling and neocortical neuronal migration. PLoS One 2012;7:e31258.

43 Jian Z, Han H, Zhang T, Puglisi J, Izu LT, Shaw JA, Onofiok E, Erickson JR, Chen YJ, Horvath B, Shimkunas R, Xiao W, Li Y, Pan T, Chan J, Banyasz T, Tardiff JC, Chiamvimonvat N, Bers DM, Lam KS, Chen-Izu Y: Mechanochemotransduction during cardiomyocyte contraction is mediated by localized nitric oxide signaling. Sci Signal 2014;7:ra27.

-44 Fukuno N, Matsui H, Kanda Y, Suzuki O, Matsumoto K, Sasaki K, Kobayashi T, Tamura S: TGF- $\beta$-activated kinase 1 mediates mechanical stress-induced IL- 6 expression in osteoblasts. Biochem Biophys Res Commun 2011;408:202-207.

45 Loeser RF, Forsyth CB, Samarel AM, Im HJ: Fibronectin fragment activation of proline-rich tyrosine kinase PYK2 mediates integrin signals regulating collagenase-3 expression by human chondrocytes through a protein kinase C-dependent pathway. J Biol Chem 2003;278:24577-24585.

46 Sugimura K, Fukumoto Y, Nawata J, Wang H, Onoue N, Tada T, Shirato K, Shimokawa H: Hypertension promotes phosphorylation of focal adhesion kinase and proline-rich tyrosine kinase 2 in rats: implication for the pathogenesis of hypertensive vascular disease. Tohoku J Exp Med 2010;222:201-210.

-47 Young SR, Hum JM, Rodenberg E, Turner CH, Pavalko FM: Non-overlapping functions for Pyk2 and FAK in osteoblasts during fluid shear stress-induced mechanotransduction. PLoS One 2011;6:e16026.

-48 Canobbio I, Cipolla L, Guidetti GF, Manganaro D, Visconte C, Kim S, Okigaki M, Falasca M, Kunapuli SP, Torti M: The focal adhesion kinase Pyk2 links Ca2+ signalling to Src family kinase activation and protein tyrosine phosphorylation in thrombin-stimulated platelets. Biochem J 2015;469:199-210.

-49 O-Uchi J, Jhun BS, Xu S, Hurst S, Raffaello A, Liu X, Yi B, Zhang H, Gross P, Mishra J, Ainbinder A, Kettlewell S, Smith GL, Dirksen RT, Wang W, Rizzuto R, Sheu SS: Adrenergic signaling regulates mitochondrial Ca2+ uptake through Pyk2-dependent tyrosine phosphorylation of the mitochondrial Ca2+ uniporter. Antioxid Redox Signal 2014;21:863-879.

50 Rotfeld H, Hillman P, Ickowicz D, Breitbart H: PKA and CaMKII mediate PI3K activation in bovine sperm by inhibition of the PKC/PP1 cascade. Reproduction 2014;147:347-356.

-51 Tsao CW, Lin CF, Wu HT, Ma CT, Huang WC, Hsieh CY, Choi PC, Young KC: Glycogen synthase kinase-3 $\beta$ is critical for interferon- $\alpha$-induced serotonin uptake in human Jurkat T cells. J Cell Physiol 2012;227:25562566.

-52 Banno Y, Nemoto S, Murakami M, Kimura M, Ueno Y, Ohguchi K, Hara A, Okano Y, Kitade Y, Onozuka M, Murate T, Nozawa Y: Depolarization-induced differentiation of PC12 cells is mediated by phospholipase D2 through the transcription factor CREB pathway. J Neurochem 2008;104:1372-1386.

-53 Xie J, Allen KH, Marguet A, Berghorn KA, Bliss SP, Navratil AM, Guan JL, Roberson MS: Analysis of the calciumdependent regulation of proline-rich tyrosine kinase 2 by gonadotropin-releasing hormone. Mol Endocrinol 2008;22:2322-2335. 